\title{
APRESENTAÇÃO DE DOSSIÊ: DIÁLOGOS EM EDUCAÇÃO
}

\author{
PRESENTATION OF DOSSIER: DIALOGUES IN EDUCATION \\ Livio Sergio Dias Claudino ${ }^{1}$ \\ Universidade Federal do Sul e Sudeste do Pará (UNIFESSPA) \\ Augusto Sarmento-Pantoja ${ }^{2}$ \\ Universidade Federal do Pará (UFPA)
}

\begin{abstract}
Resumo: A presente edição da Revista Margens Interdisciplinar conta com nove artigos, sendo 6 do Dossiê Diálogos em Educação, e 3 de temas variados. O Dossiê teve por objetivo reunir textos que tratassem dos debates contemporâneos sobre Educação, especialmente no contexto da Amazônia brasileira, incluindo temas concernentes às experiências docentes, práticas pedagógicas, gênero nas escolas e legislações relacionadas à educação, abrangendo múltiplas perspectivas teóricas, metodológica e também diferentes aplicações e resultados já observados por meio de estudos de caso.
\end{abstract}

Palavras-chave: Educação. Diálogo. Ensino.

\begin{abstract}
A presente edição da Revista Margens Interdisciplinar conta com nove artigos, sendo 6 do Dossiê Diálogos em Educação, e 3 de temas variados. O Dossiê teve por objetivo reunir textos que tratassem dos debates contemporâneos sobre Educação, especialmente no contexto da Amazônia brasileira, incluindo temas concernentes às experiências docentes, práticas pedagógicas, gênero nas escolas e legislações relacionadas à educação, abrangendo múltiplas perspectivas teóricas, metodológica e também diferentes aplicações e resultados já observados por meio de estudos de caso.
\end{abstract}

Keywords: Education. Dialogue. Teaching

\footnotetext{
${ }^{1}$ Professor Adjunto da Universidade Federal do Sul e Sudeste do Pará. Doutor em Desenvolvimento Rural. E-mail: livio.claudino@gmail.com

${ }^{2}$ Professor Adjunto da Universidade Federal do Pará. Doutor em Teoria e História Literária. E-mail: augustos@ufpa.br
} 
A edição é aberta com o texto Memória de docentes universitários: resistência e luta no campus universitário de Abaetetuba, de Mara Rita Duarte de Oliveira, que tem como objetivo central interpretar as estratégias e dispositivos de resistência docente aos modelos impositivos de instalação da Universidade heterônoma e neoprofissional, a partir da memória docente focalizando as narrativas dos docentes do Campus Universitário de Abaetetuba. A autora identifica que os docentes se baseiam na reflexão como forma de vivenciar e compreender a esfera do mundo da vida e do sistema, utilizando-se do trabalho intelectual como atividade de produção do conhecimento e na participação ativa na Universidade.

No segundo texto, Saberes e autonomia docente: um diálogo entre elementos imprescindíveis à formação do professor, de Nilce Pantoja do Carmo e Waldir Ferreira de Abreu, trata-se de uma pesquisa bibliográfica, que objetiva compreender as relações peculiares aos saberes e à autonomia, discorrendo sobre como essa interação vem se constituindo no processo de formação do professor. Para tanto, buscou-se aporte nos trabalhos de Freire (1996), Contreras (2002) e Tardif (2014). Os resultados do estudo apontam que a constituição da autonomia se associa diretamente ao aguçar dos saberes. Assim, a formação do professor deve considerar a relevância dos saberes como basilares ao fomento da autonomia docente.

No terceiro texto, BNCC, flexibilização curricular e protagonismo juvenil: movimentos atuais de "construção" do ensino médio brasileiro, a partir da Lei 13.415/2017, de Crisolita Gonçalves dos Santos Costa, a investiga a Base Nacional Comum Curricular - BNCC, a flexibilização do currículo e a ideia de protagonismo juvenil, expressa por meio da Reforma do Ensino Médio, implantada no ano de 2017. A Metodologia utilizada foi a pesquisa bibliográfica de caráter qualitativo, tendo como referenciais os documentos que tratam sobre a reforma. Baseia suas reflexões no Materialismo Histórico Dialético. As incursões apontaram que o processo proposto pela reforma desresponsabiliza o Estado pela ampla formação da juventude e seus processos de escolarização, assumindo um discurso de que o protagonismo juvenil se caracteriza como a condução dos jovens sobre seus projetos de vida, sua inserção no mercado de trabalho e por sua conduta cidadã, tendo a BNCC como instrumento alinhador desta política de educação.

O quarto texto, Fabricações de gênero na Amazônia, Brasil: estudo de caso em uma escola pública de Manaus-Am, de Dielly de Castro Silva, Jheime Matos de Sousa e Mílton Ribeiro, tem como objetivo compreender as representações de gêneros de alunos do primeiro ano do ensino médio da Escola Estadual Márcio Nery, em Manaus-AM. Partindo de observação direta e participante durantes as aulas, dinâmica em sala, exibição de uma produção audiovisual e entrevistas semiestruturadas com oito participantes deste primeiro momento, foram selecionadas apenas quatro 
para análise. A partir da análise das entrevistas, observamos como as questões de gênero constituem formas de descrever os espaços e as experiências dos alunos, seja na família ou na escola.

O quinto texto do dossiê, Recursos didáticos e inclusivos para o ensino do Meio Ambiente, de Kauê Felippe de Moraes' Bruna Rafaela Mendonça Oliveira e Luciana de Nazaré Farias' apresenta um estudo realizado junto a uma turma de discentes do PARFOR que atuam no Ensino Fundamental com a disciplina Biologia, analisando as dificuldades enfrentadas por esses professores em formação que atuam com alunos com deficiência visual (cegos/baixa visão). A metodologia com base na pesquisa qualitativa, se deu em três diferentes etapas e culminou com a realização do workshop intitulado de "Recursos Didáticos e Inclusivos para o Ensino de Meio Ambiente", onde foi construído e experimentado o uso de um "Dominó Inclusivo Sobre Meio Ambiente". Os resultados apontam que os acadêmicos apresentam experiências na educação dos alunos deficientes visuais. Porém, ainda há dificuldades em promover a educação inclusiva no ensino regular.

Fechando o Dossiê, o sexto texto, $O$ ensino religioso na rede estadual de educação do Amazonas: primeiras observações em um campo novo, de Manoel Vitor Barbosa Neto, apresenta-nos um trabalho acerca da oferta do Ensino Religioso no Estado do Amazonas, indicando os aspectos legais da disciplina a nível nacional e estadual. O mesmo utiliza documentos de caráter normativo ligados a esta disciplina a nível estadual, comparando-os a legislação nacional e outros documentos relacionados a fim de encontrar convergências e divergências entre eles. Como resultados, indica que o Ensino Religioso no Amazonas retrocedeu na forma de admissão de professores em relação as discussões travadas a nível nacional e que ficou ainda mais discrepante com o recente parecer do Conselho Nacional de Educação que estabelece a Licenciatura em Ciência(s) da(s) Religião(ões) como a formação do professor de Ensino Religioso no Brasil.

Abrindo a seção de artigos variados, o texto Colonialidade, gênero e mercado de trabalho: um diálogo entre a biopolítica e a necropolítica Maritânia Salete Salvi Rafagnin e Tiago Lemões, realiza uma leitura da classe trabalhadora no contexto moderno-colonial utilizando-se das categorias da biopolítica de Foucault e necropolítica de Mbembe, tratando de fenômenos na periferia do capitalismo. Os resultados demonstram que, a produção de valores sempre foi relacionada ao trabalho vivo, contudo, com o advento da reestruturação produtiva, baseada na acumulação flexível, as empresas, descartaram a mão-de-obra (agora sobrante ao capitalismo). Identificaram que a precarização da vida tem incidido sobre a classe trabalhadora, submetida, cada vez mais, a novas formas de exploração da força de trabalho, sendo que na biopolítica inserem-se os trabalhadores formais e na necropolítica, os informais.

$\mathrm{O}$ próximo texto, oitavo artigo do número, Cultura material e identidade: as máscaras indígenas dos povos Ticuna e Pankararu, de Rita de Cássia Domingues Lopes, discute a temática da cultura material como sendo um dos elementos importantes dos grupos humanos, assim, a produção 
e utilização desses elementos da cultura material marcam a identidade desses grupos. Apresenta dois exemplos de cultura material através das máscaras: a máscara Taí ou Tae do povo indígena Ticuna (Amazonas) e a máscara Praiá do povo indígena Pankararu (Pernambuco). Como principais resultados, indica que que os objetos, entre eles as máscaras, podem ser concebidos como elementos portadores de valores culturais, pois requer conhecimento e domínio de determinadas técnicas, do universo cosmológico, de relações próprias com o meio ambiente, a economia, a mitologia, os rituais, revelando o estilo de vida do grupo/povo e sua identidade.

O nono texto, que encerra o número, Reflexões sobre o desenvolvimento do Nordeste: $o$ pensamento Cepalino e a Teoria da Dependência, de Annahid Burnett e Pedro Maranhão, traz discussões sobre o Pensamento da Cepal e a Teoria da Dependência para fazer uma leitura sobre o processo de implantação do modo de produção capitalista no Nordeste e como se pensar modelos de desenvolvimento regional, como é o caso da Superintendência de Desenvolvimento do Nordeste. Por meio de revisão bibliográfica da literatura pertinente às abordagens concluem que o modelo de desenvolvimento absorvido pela Sudene não incorporou mudanças estruturais, resultando no aumento da concentração fundiária e das desigualdades sociais.

Desejamos a toda/os uma boa leitura! 